\title{
Recurrent Selection for Yield in Soybeans ${ }^{1,2}$
}

\author{
W. R. Fehr and L. B. Ortiz
}

ABSTRACT

Procedures have been developed for yield testing of soybeans (Glycine $\max \left(\mathbf{L}\right.$.) Merr.) that permit $S_{1}$ testing with 1 year per cycle and $S_{4}$ testing with 2 years per cycle. The principal factors in the program include efficient procedures for obtaining crossed seed by hand pollination, crossing and generation advance in Puerto Rico, and yield tests in Iowa by use of hill plots. Details for each of the three factors are discussed.

With the facilities available, expected genetic gain per year for yield was calculated for $\mathbf{S}_{1}$ testing without male sterility $\left(\mathbf{S}_{1}\right), \mathbf{S}_{1}$ testing with male sterility $\mathbf{S}_{1(\mathrm{ST})}, \mathbf{S}_{4}$ testing without male sterility $\left(\mathbf{S}_{4}\right)$, and half-sib family selection with male sterility (HF). The greatest expected gain per year was obtained with $S_{1}$ testing. There is more genetic variability among $S_{4}$ lines than among $S_{1}$ lines due to inbreeding, but expected genetic gain is less for $S_{4}$ testing because 2 years are required per cycle. $S_{1(\mathrm{ST})}$ had less expected gain per year than $S_{1}$ or $S_{4}$ testing because 2 years are required per cycle if homozygous male-fertile genotypes are evaluated. Expected genetic gain was least for HF because less genetic variability is expressed among lines than for the other three methods.

\section{INTRODUCTION}

The improvement of breeding populations by recurrent selection has been studied extensively in cross-pollinated crop species $(5,6,8,12,16,17)$. Significant population improvement has been achieved for a number of characters by using a variety of selection schemes.

In self-pollinated species, genetic advance by recurrent selection should

1 Manuscript submitted to Editorial Board September 19, 1974.

2 Joint contribution: The Iowa Agriculture and Home Economics Experiment Station, Ames, Iowa, Project No. 1179, Journal Paper No. J-7910, The Agricultural Experiment Station, Mayagüez Campus, University of Puerto Rico, Río Piedras, P.R.; and the Agricultural Research Service, U.S. Department of Agriculture.

a Professor, Dept. of Agronomy, Iowa State University; and Collaborator, Agricultural Research Service, U.S. Department of Agriculture, and Agronomist, Isabela Substation, Agricultural Experiment Station, University of Puerto Rico. The authors thank J. Domenech and A. Serrano of the Isabela Substation, University of Puerto Rico; R. Clark, ARS, USDA; and J. Bahrenfus, T. Bandstra, J. Bravo, J. Freed, D. Gedge, and D. Ivers of the Dept. of Agronomy, Iowa State University, for technical support during the project.

The financial support of the Iowa Soybean Promotion Board is gratefully acknowledged. 
be achieved by testing selfed progeny and recombining the superior individuals for the next cycle of selection. For a species in which the commercial product is an inbred cultivar, integration of population improvement and cultivar development should be possible with a minimum of extra effort.

Despite the theoretical merits of recurrent selection, little research has been reported on the actual application in self-pollinated species $(11,13,15)$. Difficulty in obtaining adequate crossed seed has been suggested as a reason for its lack of use (3). The use of genetic male sterility has been proposed to overcome this problem, but such schemes have associated drawbacks in testing progeny that are segregating for male-fertile and male-sterile plants. The number of years per cycle of selection also may be greater for populations maintained with male sterility than for populations developed and maintained by hand pollination.

This paper describes the implementation of a recurrent-selection program for yield in soybeans (Glycine $\max$ (L.) Merr.) by use of hand pollination. Procedures will be described for $S_{1}$ testing with 1 year per cycle and $S_{4}$ testing with 2 years per cycle. Estimates of expected genetic gain per year are presented for $S_{1}$ testing with and without the use of genetic male sterility, $\mathbf{S}_{4}$ testing without male sterility, and half-sib family selection with male sterility.

\section{THEORETICAL CONSIDERATIONS}

Expected genetic gain per year, $G$, from selection has been described by Eberhart (6) as

$$
G=c k \sigma_{0}{ }^{2} / y \sigma_{\text {ph }}
$$

In the formula, $c$ is an index of the parental control in the selection scheme, $k$ is the selection differential in standard units, $y$ is the number of years per cycle, $\sigma_{\theta}{ }^{2}$ is the additive genetic variance among individuals or families, and $\sigma_{p h}$ is the square root of the phenotypic variance. Genetic gain is increased by enlarging any component of the numerator or decreasing components of the denominator.

Parental control for selfed progenies is 1.0 , and $k$ is a function of the proportion of tested individuals or families used as parents for recombinations. As the percentage of selected individuals decreases, $k$ increases (6).

The magnitude of $\sigma_{o}{ }^{2 \prime}$ is a major consideration in comparing alternative recurrent-selection schemes that utilize selfed individuals. Empig, Gardner, and Compton (8) have described the $\sigma_{\theta}{ }^{2}$ component for $\mathrm{S}_{1}$ testing as $\sigma_{A}{ }^{2}+$ $C$, where $\sigma_{A}{ }^{2}$ is the additive genetic variance and $C$ is a factor related primarily to dominance. To indicate the change in $\sigma_{\theta}{ }^{2 \prime}$ with selfing, the term can be written $\sigma_{\theta}{ }^{2 \prime}=(1+F) \sigma_{A}{ }^{2}+f^{2} C$. The inbreeding coefficient, $F$, is 0 for $S_{1}$ lines, $1 / 2$ for $S_{2}, 3 / 4$ for $S_{3}$, and $7 / 8$ for $S_{4}$. The factor $f^{2}$, by which $C$ 
decreases each selfing generation, can be difficult to define (6). Nevertheless, $C$ will approach 0 with selfing. The $C$ component may inflate the estimate of genetic gain in early generation tests.

Improvement in the population mean from recurrent selection is expressed in genetic gain per year instead of genetic gain per cycle. Reducing the number of years per cycle is a principal way of increasing genetic gain per year (6). Many of the procedures described in this paper have the objective of decreasing $y$.

\section{METHODS}

\section{CROSSING PROCEDURES}

The formation of initial populations and recombination between cycles by hand pollination requires efficient crossing procedures. A combination of reduced pollen transport, reduced information recorded on the crossing tag, and elimination of emasculation has markedly increased the number of crosses made by an individual.

Parents to be crossed are grown in adjacent rows or hills to avoid transporting pollen. In most instances, pollen for a cross is within arm's reach. In a random-mating population, bulked crossed seed is planted in a row, and plant-to-plant crosses are made.

A diallel mating of selected lines frequently is used to form or maintain a population. Half of a symmetric Latin square can be used to pair parents for crossing. Use of the symmetric Latin square permits adjacent parentto-parent crosses with a minimum number of plots for each parent. Reducing space requirements for a crossing area can be important where artificial lighting is required.

The following steps are used to construct a symmetric Latin square for an even number of entries (parents) $:^{4}$ a) Write the entries in a ring (fig. 1); b) select an entry in the ring to be in the upper left-hand corner of the Latin square (starting entry); c) for the sequence of entries in the first row and column, take the entry immediately clockwise from the starting entry, then the entry immediately counterclockwise from the starting entry, then the next available entry clockwise, the next available entry counterclockwise, and so forth until the row and column are completed; d) complete the remaining columns by using the first entry in each column as the starting entry and repeat step c.

All possible pairs of parents are contained in half of the Latin square. For a diallel mating, each column (or row) is considered a mating unit. Each mating unit is independent, and crosses are not made between parents

B. Meador, Senior Data Analyst, Statistical Laboratory, Iowa State University, Ames, Iowa, personal communication. 
in different units. In each unit, pollen of the first parent is used with the second parent, pollen from the second parent is used for the third, etc. The first parent in each mating unit is used only as a male; the last parent only as a female unless reciprocal crosses are desired.

With half of the symmetric Latin square, the number of plots for each

System for establishing rows and columns in Latin square
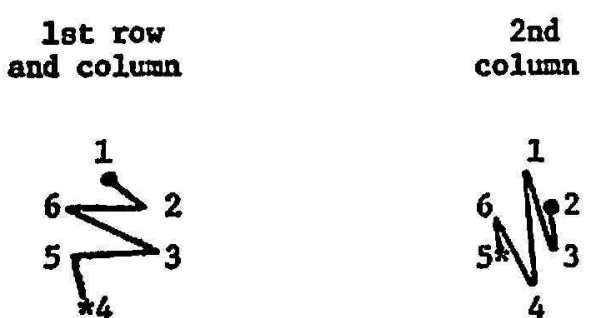

3rd
column

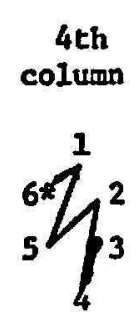

5 th
column

6th

column
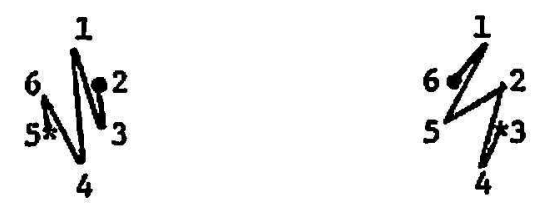

-Starting entry *Last entry

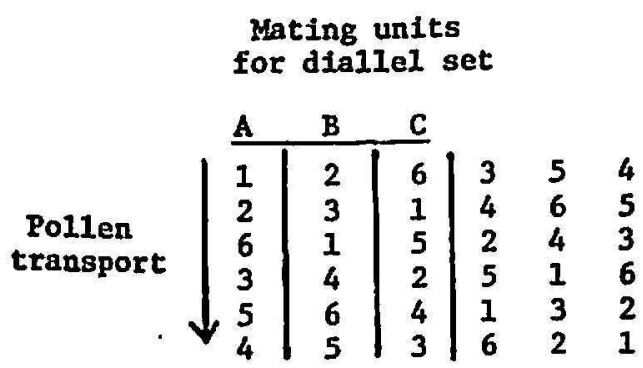

Fia. 1.-Procedure for constructing symmetric Latin square and determining mating units for a diallel mating. The procedure is illustrated with six parents.

parent in a diallel mating is $n / 2$, and the total number of plots is (n/2) (n), where $\mathrm{n}$ is the number of parents. For example, a diallel of 10 parents requires 5 plots for each parent and the total number of plots is 50 .

Mating units from a symmetric Latin square also can be used for a partial diallel mating. However, some parents will be involved in more crosses than others unless certain crosses are eliminated from the mating units.

Information required on the crossing tag is reduced by pairing parents 
to be crossed. Parentage of the cross is not needed on the tag, number of crosses and nodes with crosses is recorded only when it is not one cross at one node, date of cross can be stamped on tags preceding crossing, and name of the person is recorded only for new personnel.

Emasculation of flowers is done only for crosses of pure-line parents in which self and hybrid offspring cannot be distinguished by a genetic marker. In soybeans, the petals of the female flower are removed, and the stigma is pollinated with external pollen about 2 days before normal anthesis. R. L. Bernard ${ }^{5}$ has indicated that unemasculated flowers from which the petals have been removed will rarely produce selfed seed.

\section{NURSERY PROCEDURES}

A breeding nursery in Puerto Rico is a principal factor in our program of $S_{1}$ testing for yield with 1 year per cycle and $S_{4}$ testing with 2 years per cycle. In Puerto Rico, the day length always is shorter than the minimum required to initiate flowering in soybean genotypes adapted to Iowa (Groups I to IV), and a generation is completed in 90 days or less. This permits rapid generation advance with selfing.

Hand pollination of soybean genotypes adapted to Iowa is not possible in Puerto Rico when no artificial lighting is used. Plant size and seed number per plant also are reduced with normal day length and the amount of seed per plant can be insufficient for yield testing.

An artificial lighting system is used in Puerto Rico to permit hand pollination and increase seed production. The lighting system consists of four 1500-watt, 240-volt quartz iodide fixtures mounted on standard light poles. Each fixture faces a different quadrant of the field. A semiflood reflector was chosen to obtain a square light pattern over the area. The fixtures are mounted $8 \mathrm{~m}$ above the soil surface and pointed downward 50 degrees from vertical. A conventional 240-volt timer controls the lighting sequence on each pole.

Quartz iodide lamps emit a predominantly red wavelength that is effective for controlling photoperiodic response. Mercury vapor lamps also may be appropriate, but their wavelength is similar to that of a cool-white fluorescent lamp. Buzzell (4) and Kilen and Hartwig (14) have shown that some genotypes are photoperiodically insensitive to cool-white fluorescent light for control of flowering. Research is needed to determine if genotypes insensitive to cool-white fluorescent light in the greenhouse are insensitive to mercury vapor light under field conditions.

The land area where flowering can be controlled by lights on one pole is approximately $33 \times 33 \mathrm{~m}$. This area receives at least $3 \mathrm{fc}$ of light. Flowering begins first on the perimeter of the area and is progressively later in areas

${ }^{5}$ R. L. Bernard, U. S. Regional Laboratory, Urbana, Ill., personal communication. 
of greater light intensity. Although flowers are difficult to use for hand pollination outside the $3 \mathrm{fc}$ area, plant height and seed yield are increased, and maturity is delayed up to $25 \mathrm{~m}$ or more from the pole. Plant growth seems to be influenced by a light intensity of less than $1 \mathrm{fc}$.

Currently, we use the artificial lights to provide $24 \mathrm{hr}$ of light for 26 days after planting, after which we change to a $141 / 2-h r$ photoperiod. Flowering begins on the perimeter of the crossing area approximately 2 weeks after the $141 \%$-hr day begins. The $141 / 2$-hr sequence is used until crossing is completed; then, the lights are shut off. Crossing genotypes with widely different maturities requires staggered planting date.

TABLE 1.-Production sequence used for $S_{1}$ and $S_{4}$ testing for yield in a recurrent selection program

\begin{tabular}{|c|c|c|c|}
\hline Operation & $\begin{array}{c}\text { Light } \\
\text { provided }\end{array}$ & Location & Time \\
\hline \multicolumn{4}{|l|}{$S_{1}$ lesting } \\
\hline $\begin{array}{l}\text { Last intermating of } \mathrm{CO} \\
\text { population }\end{array}$ & Artificial & Puerto Rico & Nov. 1 to Feb. 10 \\
\hline$S_{1}$ seed produced & Artificial & Puerto Rico & Feb. 10 to May 20 \\
\hline$S_{1}$ yield test & None & Iowa & May 30 to Oct. 20 \\
\hline Intermating of selections & Artificial & Puerto Rico & Nov. 1 to Feb. 10 \\
\hline $\begin{array}{l}S_{1} \text { seed produced } \\
S_{1} \text { testing }\end{array}$ & Artificial & Puerto Rico & Feb. 10 to May 20 \\
\hline $\begin{array}{l}\text { Last intermating of } \mathrm{CO} \\
\text { population }\end{array}$ & Artificial & Puerto Rico & Nov. 1 to Feb. 10 \\
\hline$S_{1}$ seed produced & None & Puerto Rico & Feb. 10 to May 10 \\
\hline $\mathrm{S}_{2}$ seed produced & None & Puerto Rico & May 10 to Aug. 10 \\
\hline $\mathrm{S}_{3}$ seed produced & None & Puerto Rico & Aug. 10 to Nov. 10 \\
\hline $\mathrm{S}_{4}$ seed produced & Artificial & Puerto Rico & Nov. 10 to Feb. 20 \\
\hline S, yield test & None & Iowa & May 1 to Oct. 30 \\
\hline Intermating of selections & Artificial & Puerto Rico & Nov. 1. to Feb. 10 \\
\hline$S_{1}$ seed produced & None & Puerto Rico & Feb. 10 to May 10 \\
\hline
\end{tabular}

Lighting sequences currently are being investigated. A continuous 141/2$\mathrm{hr}$ day from planting may provide normal flowers for crossing and reduce the generation time in the lighted area.

Crossing is more successful in Puerto Rico than in Iowa. Approximately 80 percent of the crosses in Puerto Rico develop a pod while only 50 percent of the crosses in Iowa are successful. Reasons for the difference in crossing success are not understood. Crossing procedures in Puerto Rico and Iowa are similar. In Puerto Rico, pollen generally is available in the field from 9 in the morning to 4 in the afternoon.

The production sequence used to complete one cycle of $S_{1}$ testing per year or one cycle of $\mathbf{S}_{4}$ testing in 2 years is described in table 1. Crossing and generation advance are done in Puerto Rico, and only yield tests are 
conducted in Iowa. Generation advance for the $S_{4}$ program is by singleseed descent $(1,7)$. To maintain progeny from each $S_{0}$ family, several seeds from each $S_{0}$ plant are sown in a hill. At maturity, seeds from the hill are replanted in another hill. The procedure is repeated until one $S_{3}$ plant is harvested from each $S_{0}$ family for the yield test.

\section{TESTING PROCEDURE}

Yield tests in Iowa are conducted in hill plots for both $S_{1}$ and $S_{4}$ testing. A plot is a hill sown with 12 seeds, and hills are spaced $1 \mathrm{~m}$ apart. Two replications are planted at each of two locations. Adequate seed can be obtained from a single plant grown in Puerto Rico to sow such a yield test.

Yield and maturity are significantly correlated in hill plots $\left(r=0.42^{* *}\right.$ in $1973 \mathrm{~S}_{1}$ yield test), so maturity-date information is important for selecting superior lines over a range of maturities. For $\mathrm{S}_{4}$ lines, little intraline segregation occurs for maturity, and a visual score for maturity is adequate.

For $S_{1}$ testing, intraline heterogeneity commonly occurs, and visual estimation of average maturity for a hill is difficult. A system was developed in 1973 for objectively rating maturity of $S_{1}$ lines. Six cultivars of soybeans with the same range of maturity as the $S_{1}$ lines were included in the yield test. The checks from earliest to latest maturity were 'Wirth', 'Corsoy' 'Amsoy 71', 'Beeson', 'Wayne', and 'Cutler'. When plants of Wirth had predominantly brown pods and yellow stems, a blue paper-wire band was tied on all plants in a hill that were earlier than Wirth (completely brown pods and stem). When Amsoy 71 had yellow stems and pods (Corsoy was mature), all plants earlier than Amsoy 71 not marked previously were marked with a yellow band. When Wayne had yellow stems and pods (Beeson was mature), all plants earlier than Wayne were marked with a red band. Final maturity notes were taken when Wayne and Cutler were mature. For each plot, 10 points were given for plants marked with a blue band, 20 for yellow, 30 for red, 40 for plants of Wayne-to-Cutler maturity, and 50 for plants later than Cutler. An average maturity score was then computed for the hill. This procedure was applied to all plots in two replication at one location. The coefficient of variation for maturity was 10.6 percent, and the correlation between maturity scores in replications 1 and 2 was highly significant $(r=0.78)$. Maturity scores ranged from 11 to 43 .

\section{GAIN FROM SELECTION}

Estimates of genetic gain per cycle and per year were calculated for $S_{1}$ testing without male sterility $\left(\mathbf{S}_{1}\right), \mathbf{S}_{\mathbf{1}}$ testing with male sterility $\left(\mathbf{S}_{1(\mathrm{ST})}\right), \mathbf{S}_{\mathbf{4}}$ testing without male sterility $\left(\mathrm{S}_{4}\right)$, and half-sib family selection (HF).

Variance components were estimated from a test of $300 \mathrm{~S}_{1}$ lines grown in two replications of hill plots at two locations in Iowa during 1973 (table 2). 
TABLE 2.-Pertinent statistical information from an $S_{1}$ yield test with two replications at two locations, Ames and Stuart, Iowa, 1978

\begin{tabular}{|c|c|c|c|}
\hline Source of variation & DF & Mean Square & Expected Mean Square \\
\hline $\begin{array}{l}\text { Lines } \\
\text { Lines } \times \text { Environments } \\
\text { Error }\end{array}$ & $\begin{array}{l}299 \\
299 \\
598\end{array}$ & $\begin{array}{l}8338.1 \\
2019.8 \\
2619.5\end{array}$ & $\begin{array}{l}\sigma_{a}^{2}+2 \sigma_{g e}^{2}+4 \sigma_{o}^{2} \\
\sigma_{a}^{2}+2 \sigma_{g e}^{2} \\
\sigma_{a}^{2}\end{array}$ \\
\hline $\begin{array}{l}\text { CV (\%) } 19.1 \\
\text { Population } \bar{x} \\
\text { Selected lines } \overline{\mathrm{x}} \\
\text { Heritability } 69 \%\end{array}$ & $\begin{array}{l}232 \mathrm{~g} / \text { plot } \\
301 \mathrm{~g} / \text { plot }\end{array}$ & ${ }^{\circ}$ & $\begin{array}{l}\sigma_{e}^{2}=2619.5 \\
\sigma_{\theta 0}^{2}=0 \\
\sigma_{\theta}^{2}=1429.6\end{array}$ \\
\hline
\end{tabular}

The lines were from AP6 (CO), an unselected population involving 40 adapted parents of Group I to IV maturity that were intermated three times before selection (10).

Separate estimates of $\sigma_{g}{ }^{2 \prime}$ (additive genetic variance) and $\sigma_{\sigma}{ }^{2}$ (total genetic variance) could not be obtained from the test, so the same value was used for each. For $\mathbf{S}_{\mathbf{4}}$ testing, the genetic variance was calculated as $(1+7 / 8) \sigma_{0}{ }^{2}$, and for HF, it was $(1 / 4) \sigma_{0}^{2}$. The estimate of error was considered the same for all methods.

In calculating expected gain from selection, we have considered equal expenditures for yield testing with all methods. The cost of testing $300 \mathrm{~S}_{1}$ lines each year would be similar to that of testing 600 lines every other year for $S_{1(\mathrm{BT})}, S_{4}$, and HF. For $S_{1}$ testing, selection of 30 lines each year would constitute a 10 percent selection intensity $(k=1.75)$. With the other three methods, a selection intensity of 5 percent $(k=2.06)$ could be used on 600 lines to obtain 30 selections for recombination. The estimates of genetic gain provided in table 3 , therefore, include those for a selection intensity of 5 percent for all methods, except $S_{1}$ testing.

TABLE 3.-Expected genetic gain with four selection methods at 5 and 10 percent selection intensity with two off-season crops and one yield test per year

\begin{tabular}{|c|c|c|c|c|c|c|c|}
\hline \multirow{3}{*}{$\begin{array}{l}\text { Selection } \\
\text { Method* }\end{array}$} & \multirow{3}{*}{$\begin{array}{l}\text { Years/ } \\
\text { cycle }\end{array}$} & \multicolumn{4}{|c|}{ Expected genetic gain (g/plot) } & \multirow{2}{*}{\multicolumn{2}{|c|}{$\begin{array}{c}\text { \% deviation } / \mathrm{yr} \\
\text { from } \mathrm{S}_{1}^{* *}\end{array}$}} \\
\hline & & \multicolumn{2}{|c|}{ Per cycle } & \multicolumn{2}{|c|}{ Per year } & & \\
\hline & & $(10 \%)$ & $(5 \%)$ & $(10 \%)$ & $(5 \%)$ & $(10 \%)$ & $(5 \%)$ \\
\hline $\mathbf{S}_{\mathbf{1}}$ & 1 & 54 & - & 54 & - & - & - \\
\hline $\mathbf{S}_{1(B T)}$ & 2 & 54 & 64 & 27 & 32 & 50 & 41 \\
\hline $\mathbf{S}_{4}$ & 2 & 82 & 96 & 41 & 48 & 24 & 11 \\
\hline HF & 2 & 20 & 24 & 10 & 12 & 81 & 78 \\
\hline
\end{tabular}

$* S_{1}$ test, $S_{1(\mathrm{gT})}=S_{1}$ test with genetic male sterile, $S_{4}$ test, and HF $=$ Half-sib family test with genetic male sterile.

** Percent deviation $/ y r=\left[1.0\right.$ - (Gain per year for $S_{1(8 T)}$, $S_{\text {, }}$, or HF $\div$ Gain per year for $\$ 1)] \times 100$. 
The expected genetic gain per year is greatest for $S_{1}$ testing with one cycle per year. Although the genetic gain per cycle is equal for $S_{1(\mathrm{gT})}$ and greater for $S_{4}$ testing, 2 years are required per cycle for both $S_{1(g T)}$ and $S_{4}$.

The expected genetic gain per year with $\mathrm{S}_{4}$ testing is 24 percent less than for $\mathbf{S}_{1}$ testing when the selection intensity for both is 10 percent. When a 5 percent selection intensity is used for $S_{4}$ testing there is only an $11 \%$ difference between the two methods.

With the use of genetic male sterility, four generations are required to obtain homozygous male-fertile lines for yield testing (3). In generation 1, crossed seed is harvested on male-sterile plants; in generation 2, heterozygous male-fertile and homozygous male-sterile offspring are obtained; and in generation 3, offspring from the heterozygous male-fertile plants are grown to obtain homozygous male-fertile offspring. The homozygous male-fertile individuals can be differentiated from the heterozygous malefertile individuals only by a progeny test in generation 4 . If heterozygous male-fertile individuals are used for yield evaluation, generations 3 and 4 are not necessary, but the yield test of offspring from heterozygous malefertile individuals would be complicated by the presence of male-sterile plants in the plots. The number of male-sterile plants in each plot would vary because of sampling variation, therefore, error may increase and greater replication may be required. Plots with green male-sterile plants also may be difficult to thresh.

For determining genetic gain with $\mathbf{S}_{\mathbf{1 ( \mathrm { BT } )}}$, it was assumed that four generations would be grown in 2 years to obtain homozygous male-fertile lines and that remnant seed from heterozygous male-fertile plants would be used for recombination of selected lines. Under these assumptions, expected genetic gain per year from $S_{1 \text { (GT) }}$ is 50 percent less than for $S_{1}$ testing and 33 percent less than $S_{4}$ testing when the selection intensity is 10 percent for all methods.

The expected genetic gain per year for HF is considerably less than for the other three methods (table 3 ). This is related to lower additive genetic variance among half-sib families than among $S_{1}$ or $S_{4}$ lines.

\section{DISCUSSION}

Recurrent selection methods should be integrated into an overall cultivardevelopment program. Expected genetic gain per year, therefore, is only one of the considerations in selecting an appropriate method for yield improvement.

$S_{1}$ testing can be integrated into a variety-development program in the same manner as traditional methods of early generation testing. $S_{1}$ lines that are superior in yield can be advanced to homozygosity, and pure lines can be selected for testing as potential cultivars. Early generation 
testing in self-pollinated crops has been done primarily for identifying highyielding $F_{2}$ or $F_{3}$ families from which superior pure-line genotypes can be selected. Use of the superior $\mathrm{F}_{2}$ or $\mathrm{F}_{3}$ families per se for recombination can provide a means of hastening genetic advance in breeding programs.

$\mathrm{S}_{4}$ lines generally are adequately homogeneous for use as pure lines. Therefore, lines that are superior in the $\mathrm{S}_{4}$ yield test can be considered for direct release as cultivars.

Genetic male sterility has not been useful in recurrent selection for yield in our program because hand pollinations have provided adequate crossed seed. Genetic male sterility will be useful in recurrent-selection programs in which production of hybrid seed is limiting. For example, rapid analyses have been developed for protein and oil content of soybean seed $(2,9)$. The number of genotypes that can be evaluated may exceed the number of $\mathbf{S}_{0}$ plants that can be developed by hand pollinations. Furthermore, evaluation of seed from heterozygous male-sterile $S_{0}$ plants may be feasible. In such instances, genetic male sterility may be a useful tool for recurrent selection. In developing a recurrent-selection program, the breeder should evaluate genetic gain per year both with and without genetic male sterility for the characters under improvement.

\section{RESUMEN}

Se han desarrollado procedimientos para la soja (Glycine max (L.) Merr.) que permiten probar la $S_{1}$ para rendimiento con un año por ciclo y la $S_{4}$ con dos por ciclo. Los principales factores en el programa incluyen procedimientos eficaces para obtener semilla de cruzamientos por polinización manual, cruzamiento y generaciones avanzadas en Puerto Rico asi como pruebas de rendimiento en Iowa, Estados Unidos mediante el uso de parcelas. Se discuten los particulares de cada uno de estos factores.

Con las facilidades disponibles, la ganancia genética esperada por año para rendimiento fue calculada para la prueb ade la $S_{1}$ sin estérilidad masculina $\left(S_{1}\right)$, con esterilidad masculina $S_{1(\mathrm{BT})}$, la $S_{4}$ sin esterilidad masculina $\left(S_{4}\right)$ y la selección en familias medio-hermanas con esterilidad masculina (HF). La mayor granancia esperada por año se obtuvo mediante la prueba de la $\mathrm{S}_{1}$. Hay más variabilidad genética entre las líneas de la $S_{4}$ que entre las de la $S_{1}$ por efecto del intracruzamiento, pero la ganancia genética es menor para la prueba de la $S_{4}$ porque se requieren dos años por ciclo. La $S_{1(\text { (gT) }}$ proporcionó menos ganancia genética esperada por año que las pruebas $S_{1}$ o $S_{4}$ porque se requieren dos años por ciclo si se avaloran genotipos homozigotos androfértiles. La ganancia genética esperada más baja tuvo lugar en la HF a causa de menos expresividad en variabilidad genética entre las líneas que en la de los otros tres métodos.

\section{LITERATURE CITED}

1. Brim, Charles, A., A modified pedigree method of selection in soybeans. Crop Sci. 6: 220, 1966 .

2. - Schutz, W. M., and Collins, F. I., Nuclear magnetic resonance analysis for oil in soybeans, Glycine $\max$ (L.) Merr., with implications in selection. Crop Sci 7: 220-222, 1967. 
3. - and Stuber, C. W., Application of genetic male sterility to recurrent selection schemes in soybeans. Crop. Sci. 13: 528-530, 1973.

4. Buzzell, R. I., Inheritance of a soybean flowering response to fluorescent-daylength conditions. Can. J. Genet. Cytol. 13: 703-707, 1971.

5. Eberhart, S. A., Harrison, M. N., and Ogada, F., A comprehensive breeding system. Der Zuchter 37 : 169-174, 1967.

6. - Techniques and methods for more efficient population improvement in sorghum. p. 197-213. In N. G. P. Rao and L. R. House (ed.). Sorghum in seventies. Oxford and IBH Publishing Co., New Delhi, 1972.

7. Empig, L. T. and Fehr, W. R., Evaluation of methods for generation advance in bulk hybrid soybean populations. Crop Sci. 11 : 51-54, 1971.

8. - Gardner, C. O., and Compton, W. A., Theoretical gains for different population improvement procedures. Nebr. Agric. Exp. Sta. Misc. Publ. 26 (Revised) 22p., 1971.

9. Fehr, W. R., Collins, F. I., and Weber, C. R., Evaluation of methods for protein and oil determination in soybean seed. Crop Sci. 8: 47-49, 1968.

10. - and Ortiz, L. B., Registration of a soybean germplasm population. Crop Sci. 15: (In press).

11. Hanson, W. D., Probst, A. H., and Caldwell, B. E., Evaluation of a population of soybean genotypes with implications for improving self-pollinated crops. Crop Sci. 7: 99-103, 1967.

12. Hanson, C. H., Busbice, T. H., Hill, Jr., R. R., Hunt, O. J., and Oakes, A. J., Directed mass selection for developing multiple pest resistance and conserving germplasm in alfalfa. J. Environ. Qual. 1: 106-111, 1972.

13. Khadr, F. H. and Frey, K. J., Effectiveness of recurrent selection in oat breeding (Avena saliva L.). Crop Sci. 5: 349-354, 1965.

14. Kilen, T. C., and Hartwig, E. E., Inheritance of a light-quality sensitive character in soybeans. Crop Sci. 11: 559-561, 1971.

15. Matzinger, D. F. and Wernsman, E. A., Four cycles of mass selection in a synthetic variety of an autogamous species Nicotiana tabacum L. Crop Sci. 8: 239$243,1968$.

16. Moll, R. H. and Robinson, H. F., Observed and expected response in four selection experiments in maize. Crop Sci. 6: 319-324, 1966.

17. Sprague, G. F., Quantitative genetics in plant improvement, 1966. p. 315-347. In K. J. Frey (ed.). Plant breeding. Iowa State University Press, Ames, 1966. 